\title{
Effect of low-density lipoproteins, spermatozoa concentration and glycerol on functional and motility parameters of bull spermatozoa during storage at $4{ }^{\circ} \mathrm{C}$
}

\author{
Oscar Vera-Munoz ${ }^{1,2}$, Lamia Amirat-Briand ${ }^{1}$, Djemil Bencharif ${ }^{1}$, Marc Anton $^{3}$, Serge Desherces ${ }^{4}$, Eric Shmitt ${ }^{4}$, \\ Chantal Thorin ${ }^{1}$ and Daniel Tainturier ${ }^{1}$
}

An extender has been developed with low-density lipoproteins (LDLs) that eliminates the microbial risks associated with the use of whole egg yolk. The objective of this study was to assess the effects of substituting egg yolk with LDLs for use as an extender in sperm preservation at $4{ }^{\circ} \mathrm{C}$, as well as on spermatozoa motility, plasma membrane and acrosome integrity, at two different concentrations $\left(80 \times 10^{6}\right.$ and $240 \times 10^{6}$ sperm per $\left.\mathrm{ml}\right)$ for 8 days and to evaluate glycerol toxicity in both extenders. A total of 12 ejaculates were collected from three bulls. Spermatozoa motility was examined using computer-assisted semen analysis. Plasma membrane integrity was determined using the hypo-osmotic swelling test and acrosome integrity with the fluorescein isothiocyanate-Pisum sativum agglutinin test. The semen was subsequently divided into four aliquots and diluted with Tris-egg yolk-glycerol (TEG), Tris-egg yolk without glycerol (TE), LDL with glycerol $\left(\mathrm{LDL}^{+}\right)$and $\mathrm{LDL}$ without glycerol $\left(\mathrm{LDL}^{-}\right)$, at $80 \times 10^{6}$ and $240 \times 10^{6}$ sperm per ml. This study showed that the $\mathrm{LDL}^{+}$and $\mathrm{LDL}^{-}$extenders were more effective at preserving spermatozoa motility, plasma membrane integrity and acrosome integrity than TEG and TE $(P<0.05)$ during 8 days of incubation. After 3 days of incubation, a toxicity of glycerol was observed in TEG, whereas no significant difference was observed between $\mathrm{LDL}^{+}$and $\mathrm{LDL}^{-}$. We can therefore conclude that the $\mathrm{LDL}$ extender can be used to refrigerate semen at $4^{\circ} \mathrm{C}$ instead of TEG and TE at $80 \times 10^{6}$ and $240 \times 10^{6}$ sperm per ml for elite bulls. This finding can be used to define a policy for the storage of high-quality bull semen.

Asian Journal of Andrology (2011) 13, 281-286; doi:10.1038/aja.2010.84; published online 29 November 2010

Keywords: bull semen; glycerol; low-density lipoproteins; membrane integrity; motility; refrigeration

\section{INTRODUCTION}

Semen cryopreservation contributes to the expansion of reproductive techniques, such as artificial insemination (AI) and in vitro fertilization. ${ }^{1}$ The extensive use of AI has enabled an accelerated rate of genetic selection and improvement in animal production, especially in dairy cattle. ${ }^{1}$ Cryopreservation extends the availability of sperm for fertilization; however, the fertilizing potential of the frozen-thawed sperm is reduced because of alterations in the structure and physiology of the spermatozoa; ${ }^{2,3}$ these alterations reduce the spermatozoon's life span and fertilizing ability. ${ }^{1}$ Spermatozoa motility, as with other biological processes, is sensitive to temperature and decreases progressively as spermatozoa are cooled. ${ }^{4}$ This 'cold shock' effect results in an irreversible loss of motility. ${ }^{5}$ 'Cold shock' can be prevented by controlling the rate of cooling and by adding protective compounds to semen extenders such as egg yolk. ${ }^{5,6}$ Pace and Graham ${ }^{7}$ purified egg yolk and observed that the low-density lipoprotein (LDL) fraction showed cryoprotective properties. Many other studies have confirmed that the LDL fraction has cryoprotective action. ${ }^{8-11}$ Egg yolk can therefore be replaced with fractions of LDLs in semen extenders for freezing. An advantage of an LDL extender over a standard egg yolk extender is that it has a less complex chemical composition and does not interfere with microscopic observations. ${ }^{10}$ Egg yolk and LDLs are considered nonpenetrating cryoprotectants; they do not cross sperm plasma membrane and act extracellularly. ${ }^{12}$ Therefore, they may protect the plasma membrane or act as a solute, lowering the freezing temperature of the medium and decreasing extracellular ice formation. ${ }^{13,14}$

Male animals can be classified as 'good or bad freezers' depending on the aptitude of their semen to support freezing with little cryodamage. ${ }^{3}$ Often the selection of the reproductive bulls is based on the capacity of semen to support freezing. Thus, many bulls of high genetic value cannot be selected to produce frozen doses. Semen refrigeration could be a viable alternative for such cases. The advantage of using semen cooled to $4{ }^{\circ} \mathrm{C}$ is that the $\mathrm{AI}$ doses contain a higher percentage of motile spermatozoa compared with frozen-thawed semen at the same concentration. Bulls with a high genetic value could therefore be used even if they are 'bad freezers'. This technique of refrigeration at $4{ }^{\circ} \mathrm{C}$ could also be useful in countries where it is difficult to obtain liquid nitrogen.

${ }^{1}$ Laboratory of Biotechnology and Pathology of Reproduction, ONIRIS, Nantes-Atlantic College of Veterinary Medicine and Food Science, 44307 Nantes, France; ${ }^{2}$ Facultad de Ciencias Veterinarias, Instituto de Reproducción Animal Abraham Hernández Prado, Universidad Central de Venezuela, Maracay 2101, Aragua, Venezuela; ${ }^{3}$ Groupe Physicochimie des Emulsions, Laboratoire d'Etude des Interactions des Molécules Alimentaires, Institut National de la Recherche Agronomique, 44316 Nantes Cedex 3, France and ${ }^{4}$ IMV Technologies, l'Aigle 61300, France

Correspondence: Dr L Amirat-Briand (Lamia.briand-amirat@oniris-nantes.fr)

Received: 19 March 2010; Revised: 18 June 2010; Accepted: 27 June 2010; Published online: 29 November 2010 
One of the main problems with refrigerating the semen to $4{ }^{\circ} \mathrm{C}$ is 'cold shock', and this could be reduced by slow cooling the sperm in the presence of cryoprotective agents such as egg yolk, lecithin, glycerol and others. ${ }^{15}$ However, there are no studies carried out on the bull concerning the success of refrigeration when egg yolk is replaced by LDLs in the presence or absence of other cryoprotective agents such as glycerol, or on the effects on sperm motility and membrane functionality. The purpose of this study was to assess the effect of bovine semen dilution with an LDL extender on spermatozoal motility and plasma membrane functionality after refrigeration to $4{ }^{\circ} \mathrm{C}$, using Trisegg yolk-glycerol (TEG) as control, Tris-egg yolk without glycerol (TE) as a second control, $8 \% \mathrm{LDL}$ with glycerol $\left(\mathrm{LDL}^{+}\right)$and $\mathrm{LDL}$ without glycerol $\left(\mathrm{LDL}^{-}\right)$at two different dilutions: $80 \times 10^{6}$ sperm per $\mathrm{ml}$ (normally recommended for frozen semen ${ }^{3,16}$ ) and $240 \times 10^{6}$ sperm per $\mathrm{ml}$ (predilution recommended by Benson et al., ${ }^{17}$ the greater volume of seminal plasma helps to maintain semen quality at $4{ }^{\circ} \mathrm{C}$ ). Glycerol is generally used for freezing semen; however, it was tested here to determine whether the use of LDL extenders 'ready to use for freezing semen' containing glycerol will be toxic and detrimental for semen at $4{ }^{\circ} \mathrm{C}$. In this study the semen was examined every $24 \mathrm{~h}$ for 8 days.

\section{MATERIALS AND METHODS}

\section{Semen collection and prerefrigeration analysis}

Semen samples ( $n=12$ ejaculates) were collected from three Holstein bulls (Bos taurus) 3-4 years old, using an artificial vagina; the bulls were selected for good semen quality, in accordance with the standards described for bull semen. ${ }^{15}$ After collection and before refrigeration, the semen was analyzed for volume, sperm motility, morphology, concentration, plasma membrane integrity and acrosome integrity.

\section{Assessment of fresh sperm motility using computer-assisted sperm analysis}

The sperm motility of each ejaculate was analyzed using a computerassisted sperm analysis (CASA) system (HTM-CEROS-Ultimate; Hamilton Thorne Biosciences, Beverly, MA, USA); the CASA system had been configured for bovine semen analyses. To assess the motility of the fresh ejaculate, the sample was diluted to a final concentration of $25 \times 10^{6}$ spermatozoa per $\mathrm{ml}$ in Tris buffer $\left(200 \mathrm{mmol}^{-1}\right.$, free of egg yolk and glycerol) supplemented with citric acid $\left(70 \mathrm{mmoll}^{-1}\right)$, fructose $\left(55 \mathrm{mmol}^{-1}\right)$, penicillin (50 $\left.000 \mathrm{IU}\right)$ and gentamicin $(25 \mathrm{mg})$ into sterile water and prewarmed to $37{ }^{\circ} \mathrm{C}$ for $10 \mathrm{~min}$. Sample $(2 \mu \mathrm{l})$ was placed in a 20-mm standard counting chamber (SC20.01.FA; Leja, Nieuw-Vennep, the Netherlands). A minimum of 20 fields was selected for each analysis.

\section{Assessment of fresh spermatozoa morphology}

Sperm morphology was assessed on prepared semen smears stained with eosin-nigrosin and observed under the microscope at $\times 1000$ magnification (Olympus CK2, ULWCD 0.30; Olympus Optical Co. Ltd, London, UK). The criterion used was that of the American Society of Theriogenology, ${ }^{18}$ and 200 cells were evaluated for each sample.

\section{Assessment of fresh spermatozoa membrane integrity}

Plasma membrane integrity was determined using the hypo-osmotic swelling test. ${ }^{19}$ A volume of $100 \mu \mathrm{l}$ of each ejaculate were mixed with $1 \mathrm{ml}$ of a hypotonic solution ( $100 \mathrm{mOsM}$ per $\mathrm{kg} \mathrm{H}_{2} \mathrm{O}$ ) prepared with $75 \mathrm{mmol}^{-1}$ fructose and $25 \mathrm{mmol}^{-1}$ trisodium citrate in distilled water. The mixture was incubated at $37^{\circ} \mathrm{C}$ for $60 \mathrm{~min}$. After incubation, $15 \mu \mathrm{l}$ of the mixture was placed on a slide, covered and observed under the microscope (Olympus CK2, ULWCD 0.30) at $\times 400$ magnification. The spermatozoa were classified according to the presence or absence of swollen tail. ${ }^{20,21}$ At least 200 spermatozoa were observed and recorded to express the results as a percentage. When exposed to hypo-osmotic stress, normal spermatozoa swell because of the influx of water. The plasma membrane surrounding the tail fibers appears to be more loosely attached than the membrane surrounding the head; hence, the tail regions show the swelling effect more clearly. ${ }^{20,21}$

\section{Assessment of fresh spermatozoa acrosome integrity}

Acrosome integrity was assessed using the fluorescein isothiocyanatePisum sativum agglutinin (FITC-PSA) test according to Mendoza et $a$. $^{22}$ Aliquots of sperm were used to prepare smears on microscope slides. After air drying, sperm smears were fixed in absolute methanol for $15 \mathrm{~min}$ and allowed to dry. The methanol-treated smears were incubated for $10 \mathrm{~min}$ at room temperature in a moisture chamber with a solution of FITC-conjugated PSA (50 $\mu \mathrm{g} \mathrm{ml}^{-1}$; Sigma, St Louis, MI, USA) in phosphate-buffered saline. The slides were washed in a stream of water to remove any unbound probe before being immersed in water for at least $15 \mathrm{~min}$. After drying, smears were examined using epifluorescence microscopy (LEYKA DM-IRB linked to a Nikon digital camera DXM, New York, USA). Pictures were analyzed with LUCIA G (images analysis software, Nikon). The spermatozoa ( $n=200)$ were classified as follows: (i) positive spermatozoa with selective staining of the whole acrosome; and (i) negative spermatozoa with no stain uptake. The results were expressed in percentages of positive spermatozoa.

\section{Preparation of the extenders}

All four of the extenders used in this study were prepared in our laboratory, using reagent-grade chemicals purchased from Sigma or Merck (Rahway, NJ, USA). Extender 1: TEG, supplemented with $200 \mathrm{mmol}^{-1}$ Tris, $70 \mathrm{mmol} \mathrm{l}^{-1}$ citric acid monohydrate, $55 \mathrm{mmol} \mathrm{l}^{-1}$ fructose, 6.4\% (v/v) glycerol, 20\% (v/v) egg yolk, $0.025 \%(\mathrm{w} / \mathrm{v})$ gentamicin, $50000 \mathrm{IU}$ (IU per $100 \mathrm{ml}$ ) penicillin, $0.05 \%(\mathrm{w} / \mathrm{v})$ lincomycin and $0.1 \%(\mathrm{w} / \mathrm{v})$ spectinomycin. TEG was used as a control in each experimental series, as it is considered a standard egg yolk extender. Extender 2: TE, supplemented in the same way as TEG, but without glycerol. TE was also used as a control in each experimental series. Extender 3: $\mathrm{LDL}^{+}$, the extender with $8 \% \mathrm{LDL}$ dry matter was prepared in our laboratory according to the technique described by Moussa et al. ${ }^{9}$ ( $8 \%$ is the optimum concentration found in bull semen by Moussa et al. $\left.{ }^{9}\right)$. This extender was supplemented in the same way as the others with glycerol. Extender $4: 8 \% \mathrm{LDL}^{-}$, supplemented in the same way as extender 3 , but without glycerol.

\section{Refrigeration of the diluted semen at $4{ }^{\circ} \mathrm{C}$ for 8 days}

No more than 5 min after sperm collection, each ejaculate was divided into four fractions: the first fraction was diluted with TEG, the second with TE, the third fraction with $\mathrm{LDL}^{+}$and the fourth fraction with $\mathrm{LDL}^{-}$. Each fraction was then divided into two aliquots: the first was diluted to $80 \times 10^{6}$ spermatozoa per $\mathrm{ml}$, and the second to $240 \times 10^{6}$ spermatozoa per $\mathrm{ml}$. The tubes containing the dilutions were cooled from 37 to $4{ }^{\circ} \mathrm{C}$ over $1.5 \mathrm{~h}$; aliquots were then prepared for each evaluation and maintained at $4{ }^{\circ} \mathrm{C}$ for 8 days in a cold chamber.

\section{Semen evaluation during the refrigeration period (8 days)}

Assessment of semen motility. The post-dilution and cooling motility of the sperm was assessed using CASA system every 24 h over 8 days at $4{ }^{\circ} \mathrm{C}$, by placing $4 \mu \mathrm{l}$ of semen between the slide and coverslip. The 
CEROS-Ultimate semen analyzer was used in the same way as for fresh semen.

Assessment of membrane integrity. Plasma membrane integrity was assessed using the hypo-osmotic swelling test, ${ }^{19}$ as described for fresh semen, every $24 \mathrm{~h}$ during the 8 days of refrigeration at $4{ }^{\circ} \mathrm{C}$.

Assessment of acrosome integrity. Acrosome integrity was assessed using evaluated the FITC-PSA test according to Mendoza et al., ${ }^{22}$ as described for fresh semen, every $24 \mathrm{~h}$ during the 8 days of refrigeration at $4{ }^{\circ} \mathrm{C}$.

Statistical analysis. The data obtained from the experiments were analyzed using mixed effects analysis of variance (ANOVA) (SPLUS Statistical Program; Insightful Corporation, Seattle, WA, USA). $P \leqslant 0.05$ were considered significantly different.

\section{RESULTS}

The semen characteristics from the three bulls (12 ejaculates) show that semen quality was in the normal range according to the standards described for bull semen.

\section{Sperm morphology}

The percentages of normal sperm were $78.9 \pm 4.4 \%$ in fresh sperm, whereas abnormal sperm in the same sample was found to be $21.0 \pm 4.4 \%$. The percentage of major defects and total defects were coherent with normal standard values.

\section{Sperm motility}

Sperm motility: dilution at $240 \times 10^{6}$ sperm per $\mathrm{ml}$. The motility of the spermatozoa diluted at $240 \times 10^{6}$ sperm per $\mathrm{ml}$ in four different extenders over 8 days is given in Table 1 . The results obtained show that from $24 \mathrm{~h}$ after the start of the refrigeration process at $4{ }^{\circ} \mathrm{C}$, spermatozoal motility progressively declines until day 8 of incubation. This decrease was statistically significant $(P<0.001)$ from day 3 compared with the initial percentage recorded on day 0 (fresh semen) (83.8 $\pm 3.2 \%$; Table 1). Table 1 shows that values obtained with $\mathrm{LDL}^{+}$and $\mathrm{LDL}^{-}$were always higher than those obtained with TEG and TE. However, the significant differences between these extenders were only detected between days 6 and 8 of incubation $(P<0.001)$. In the egg yolk extender, a significant difference on motility results was observed in presence or absence of glycerol after 3 days of incubation at $4{ }^{\circ} \mathrm{C}$. No significant difference was observed between $\mathrm{LDL}^{+}$and $\mathrm{LDL}^{-}$on motility results.

Sperm motility: dilution at $80 \times 10^{6}$ sperm per $\mathrm{ml}$. The percentage of sperm motility at $80 \times 10^{6}$ sperm per $\mathrm{ml}$ in the four extenders over 8 days of refrigeration at $4{ }^{\circ} \mathrm{C}$ is shown in Table 1 . A progressive reduction in spermatozoa motility was observed from $24 \mathrm{~h}$ of refrigeration until day 8 , similar to that observed at a dilution of $240 \times 10^{6}$ sperm per $\mathrm{ml}$. This decrease was significantly lower from day 3 than the initial percentage motility $(83.83 \pm 3.25 \%)$ for all the extenders used in this study $(P<0.001)$. Table 1 shows that the spermatozoa motility percentages obtained with $\mathrm{LDL}^{+}$and $\mathrm{LDL}^{-}$were also higher than those obtained with the TEG and TE extenders; however, these differences were not statistically significant until days 5 to 8 of refrigeration.

The sperm motility percentages recorded at the dilution of $80 \times 10^{6}$ sperm per $\mathrm{ml}$ were higher than the corresponding percentages recorded at $240 \times 10^{6}$ sperm per ml, particularly at the end of the refrigeration period $(P<0.05)$. The statistical analysis (ANOVA) shows that the refrigeration time has a significant effect on sperm motility $(P<0.0001)$

The differences observed between sperm motility at different dilutions in all the extenders indicates that a dilution of $80 \times 10^{6}$ sperm per $\mathrm{ml}(P<0.05)$ provides superior preservation of sperm motility.

\section{Plasma membrane integrity}

Plasma membrane integrity: dilution at $240 \times 10^{6}$ sperm per $m l$. Table 2 shows the percentages of intact spermatozoal plasma membranes at a dilution of $240 \times 10^{6}$ sperm per $\mathrm{ml}$ in four extenders over 8 days at $4{ }^{\circ} \mathrm{C}$. A gradual decline in plasma membrane integrity was observed after $24 \mathrm{~h}$ of refrigeration; this continued until day 8 . From day 3, percentages of membrane integrity were significantly lower than the initial values recorded in fresh semen (day $0=80.6 \pm 2.2 \%, P<0.0005$ ). Table 2 shows the intact plasma membrane percentages obtained with the $\mathrm{LDL}^{+}$and $\mathrm{LDL}^{-}$extenders; these were higher than the values obtained with TEG and TE, although this difference only became statistically significant from day 6 to day $8(P<0.05)$. The mean percentages of plasma membrane integrity at the end of the refrigeration period (day 8) are presented in Table 2. The values for $\mathrm{LDL}^{+}$and $\mathrm{LDL}^{-}$were significantly higher than those obtained with TEG and TE $(P<0.001)$; glycerol effect was also observed here in the egg yolk extender.

Table 1 Mean ( \pm s.d.) percentage motility of spermatozoa at $240 \times 10^{6}$ and $80 \times 10^{6}$ sperm per ml in extenders TEG, TE, LDL ${ }^{+}$and LDL $^{-}$over the 8 days at $4{ }^{\circ} \mathrm{C}$ (computer-assisted semen analysis system)

\begin{tabular}{|c|c|c|c|c|c|c|c|c|}
\hline \multirow{2}{*}{ Days } & \multicolumn{4}{|c|}{$240 \times 10^{6}$ sperm per $\mathrm{ml}$ in extenders } & \multicolumn{4}{|c|}{$80 \times 10^{6}$ sperm per $\mathrm{ml}$ in extenders } \\
\hline & TEG & $T E$ & $L D L^{+}$ & $L D L^{-}$ & TEG & $T E$ & $L D L^{+}$ & $L D L^{-}$ \\
\hline 0 & $83.8 \pm 3.2^{x a}$ & $83.8 \pm 3.2^{x a}$ & $83.8 \pm 3.2^{x a}$ & $83.8 \pm 3.2^{x a}$ & $83.8 \pm 3.2^{x c}$ & $83.8 \pm 3.2^{x c}$ & $83.8 \pm 3.2^{x c}$ & $83.8 \pm 3.2^{x c}$ \\
\hline 1 & $79.5 \pm 5.1^{x a}$ & $82.0 \pm 3.2^{x a}$ & $80.2 \pm 5.3^{x a}$ & $82.2 \pm 2.3^{x a}$ & $78.3 \pm 6.1^{x c}$ & $80.5 \pm 4.2^{x c}$ & $81.7 \pm 5.9^{x c}$ & $83.0 \pm 2.6^{x c}$ \\
\hline 2 & $77.2 \pm 5.2^{x a}$ & $78.8 \pm 1.8^{x a}$ & $79.3 \pm 5.3^{\text {xa }}$ & $80.2 \pm 4.6^{x a}$ & $74.8 \pm 6.2^{x d}$ & $78.33 \pm 6.3^{x c}$ & $80.8 \pm 5.7^{x d}$ & $81.5 \pm 3.1^{\mathrm{xc}}$ \\
\hline 3 & $74.2 \pm 7.5^{\mathrm{yb}}$ & $75.5 \pm 4.7^{\text {уа }}$ & $77.0 \pm 4.7^{\text {уа }}$ & $77.7 \pm 4.0^{\text {уа }}$ & $72.0 \pm 5.4^{\mathrm{yd}}$ & $74.6 \pm 5.2^{\mathrm{yc}}$ & $78.5 \pm 4.6^{y d}$ & $79.5 \pm 3.7^{y c}$ \\
\hline 4 & $71.2 \pm 9.1^{\mathrm{yb}}$ & $72.0 \pm 5.3^{\text {уа }}$ & $73.5 \pm 5.6^{\text {ya }}$ & $73.2 \pm 6.2^{\text {yа }}$ & $70.3 \pm 7.8^{\mathrm{yc}}$ & $73.2 \pm 7.0^{\mathrm{yc}}$ & $77.0 \pm 5.7^{\mathrm{yd}}$ & $77.2 \pm 4.7^{y c}$ \\
\hline 5 & $64.2 \pm 11.5^{\mathrm{yb}}$ & $66.5 \pm 3.4^{\text {ya }}$ & $66.0 \pm 6.9^{\text {ya }}$ & $66.2 \pm 4.3^{\mathrm{ya}}$ & $63.3 \pm 15.5^{y c}$ & $68.0 \pm 6.4^{y c}$ & $75.2 \pm 5.1^{y d}$ & $73.7 \pm 3.3^{y c}$ \\
\hline 6 & $57.6 \pm 13.5^{\mathrm{yb}}$ & $58.6 \pm 5.9^{y b}$ & $63.3 \pm 8.7^{\text {ya }}$ & $61.6 \pm 8.9^{\text {ya }}$ & $59.7 \pm 15.9^{y c}$ & $64.8 \pm 8.6^{\mathrm{yc}}$ & $71.2 \pm 9.9^{y d}$ & $69.8 \pm 5.8^{\mathrm{yc}}$ \\
\hline 7 & $40.8 \pm 25.2^{\mathrm{yb}}$ & $48.3 \pm 10.3^{\mathrm{yb}}$ & $50.5 \pm 20.9^{\text {yа }}$ & $55.0 \pm 11.0^{\text {ya }}$ & $47.5 \pm 23.8^{y c}$ & $55.8 \pm 9.1^{\mathrm{yd}}$ & $65.2 \pm 11.4^{\mathrm{yd}}$ & $61.7 \pm 4.8^{y c}$ \\
\hline 8 & $17.5 \pm 14.8^{\mathrm{yb}}$ & $24.0 \pm 12.8^{y b}$ & $27.3 \pm 17.8^{\text {ya }}$ & $32.3 \pm 13.1^{\text {ya }}$ & $34.2 \pm 24.6^{y d}$ & $42.6 \pm 13.2^{\mathrm{yc}}$ & $58.2 \pm 14.9^{y c}$ & $53.0 \pm 5.8^{y c}$ \\
\hline
\end{tabular}

Abbreviations: $\mathrm{LDL}^{+}, \mathrm{LDL}$ with glyceroland; $\mathrm{LDL}^{-}, \mathrm{LDL}$ without glycerol; TE, Tris-egg yolk without glycerol; TEG, Tris-egg yolk-glycerol.

${ }^{\mathrm{a}, \mathrm{b}}$ Differences $(P<0.05)$ between the extenders TEG, TE, $\mathrm{LDL}^{+}$and $\mathrm{LDL}^{-}$at $240 \times 10^{6}$ sperm per $\mathrm{ml}$.

c, d Differences $(P<0.05)$ between the extenders TEG,TE, $\mathrm{LDL}^{+}$and $\mathrm{LDL}^{-}$at $80 \times 10^{6}$ sperm per $\mathrm{ml}$ within a same time period.

$x, y$ differences $(P<0.05)$ between the initial value of motility and the values in the refrigeration period ( 8 days). 
Table 2 Mean ( \pm s.d.) percentage of sperm plasma membrane integrity (HOST) at $240 \times 10^{6}$ and $80 \times 10^{6}$ sperm per ml in extenders TEG, TE, $\mathrm{LDL}^{+}$and $\mathrm{LDL}^{-}$, over the 8 days at $4{ }^{\circ} \mathrm{C}$

\begin{tabular}{|c|c|c|c|c|c|c|c|c|}
\hline \multirow{2}{*}{ Days } & \multicolumn{4}{|c|}{$240 \times 10^{6}$ sperm per $\mathrm{m} /$ in extenders } & \multicolumn{4}{|c|}{$80 \times 10^{6}$ sperm per $\mathrm{ml}$ in extenders } \\
\hline & $T E G$ & $T E$ & $L D L^{+}$ & $L D L^{-}$ & $T E G$ & $T E$ & $L D L^{+}$ & $L D L^{-}$ \\
\hline 0 & $80.6 \pm 2.2^{x a}$ & $80.6 \pm 2.2^{x a}$ & $80.6 \pm 2.2^{x a}$ & $80.6 \pm 2.2^{x a}$ & $80.6 \pm 2.2^{x c}$ & $80.6 \pm 2.2^{x c}$ & $80.6 \pm 2.2^{x c}$ & $80.6 \pm 2.2^{x c}$ \\
\hline 2 & $75.3 \pm 5.4^{\mathrm{xa}}$ & $77.8 \pm 1.4^{\mathrm{xa}}$ & $78.1 \pm 5.7^{\text {ха }}$ & $78.1 \pm 4.3^{\mathrm{xa}}$ & $72.8 \pm 6.1^{x c}$ & $76.43 \pm 6.3^{x c}$ & $78.9 \pm 6.0^{\mathrm{xc}}$ & $80.6 \pm 3.3^{x c}$ \\
\hline 3 & $72.0 \pm 7.6^{\mathrm{yb}}$ & $73.3 \pm 5.6^{\text {ya }}$ & $75.1 \pm 5.2^{\text {ya }}$ & $76.1 \pm 4.6^{\text {ya }}$ & $69.9 \pm 7.5^{\mathrm{yc}}$ & $78.81 \pm 5.0^{y c}$ & $76.8 \pm 4.6^{y c}$ & $77.8 \pm 3.9^{\mathrm{yc}}$ \\
\hline 4 & $68.6 \pm 9.5^{y b}$ & $70.0 \pm 5.6^{\text {ya }}$ & $71.3 \pm 6.4^{\text {ya }}$ & $71.3 \pm 5.9^{\text {ya }}$ & $68.6 \pm 7.2^{\mathrm{yc}}$ & $70.5 \pm 7.2^{\mathrm{yc}}$ & $75.1 \pm 5.8^{\mathrm{yc}}$ & $75.5 \pm 5.3^{\mathrm{yc}}$ \\
\hline 7 & $38.4 \pm 24.0^{y b}$ & $46.0 \pm 10.3^{y b}$ & $48.0 \pm 21.4^{\text {ya }}$ & $52.3 \pm 11.1^{\text {ya }}$ & $45.3 \pm 23.4^{y c}$ & $55.7 \pm 8.0^{y c}$ & $63.0 \pm 10.6^{y c}$ & $58.9 \pm 4.6^{\mathrm{yc}}$ \\
\hline 8 & $15.7 \pm 13.8^{y b}$ & $21.3 \pm 12.8^{\mathrm{yb}}$ & $25.1 \pm 16.9^{\text {ya }}$ & $29.3 \pm 12.2^{\text {ya }}$ & $32.1 \pm 24.4^{\mathrm{yd}}$ & $39.6 \pm 13.0^{y d}$ & $55.9 \pm 14.3^{y c}$ & $50.9 \pm 5.3^{\text {yc }}$ \\
\hline
\end{tabular}

Abbreviations: HOST, hypo-osmotic swelling test; LDL ${ }^{+}$, LDL with glyceroland; LDL ${ }^{-}$, LDL without glycerol; TE, Tris-egg yolk without glycerol; TEG, Tris-egg yolk-glycerol. ${ }^{\mathrm{a}, \mathrm{b}}$ Differences $(P<0.05)$ between the extenders TEG,TE, $\mathrm{LDL}^{+}$and $\mathrm{LDL}^{-}$at $240 \times 10^{6}$ sperm per $\mathrm{ml}$.

${ }^{c,}{ }^{d}$ Differences $(P<0.05)$ between the extenders TEG,TE, $\mathrm{LDL}^{+}$and $\mathrm{LDL}^{-}$at $80 \times 10^{6}$ sperm per $\mathrm{ml}$ within a same time period.

${ }^{x}, y$ Differences $(P<0.05)$ between the initial value of plasma membrane integrity and the values in the refrigeration period $(8$ days).

Plasma membrane integrity: dilution at $80 \times 10^{6}$ sperm per $\mathrm{ml}$. Table 2 shows the mean percentages of spermatozoa with intact plasma membranes diluted at $80 \times 10^{6}$ sperm per $\mathrm{ml}$ in the four extenders and refrigerated at $4{ }^{\circ} \mathrm{C}$ over 8 days. A progressive decline in plasma membrane integrity was observed from $24 \mathrm{~h}$ after the start of the study; this decrease continued until day 8 of refrigeration. On day 3 , the percentages were significantly lower $(P<0.05)$ than the initial value recorded on day 0 . The mean percentage of plasma membrane integrity in fresh semen (day 0 ) was $80.6 \pm 2.2 \%$. Table 2 shows that the values obtained with $\mathrm{LDL}^{+}$and $\mathrm{LDL}^{-}$were always higher than those obtained with TEG and TE, although these differences were only significant on days 6, 7 and 8. A favorable significant difference was observed for $\mathrm{LDL}^{-}$ and $\mathrm{LDL}^{+}(P<0.001)$.

Table 2 shows the results obtained for plasma membrane integrity at a dilution of $80 \times 10^{6}$ sperm per $\mathrm{ml}$, the observed reduction in membrane integrity was less marked than that observed at $240 \times 10^{6}$ sperm per $\mathrm{ml}$. However, the statistical analysis did not reveal any significant difference with respect to the sperm concentration, but there were favorable significant differences in the results obtained with $\mathrm{LDL}^{+}$or $\mathrm{LDL}^{-}$. The values presented in Table 2 show a significant effect of time and type of extenders on plasma membrane integrity. The statistical analysis shows that time has a significant effect on plasma membrane integrity $(P<0.0001)$. However, there is no significant difference in plasma membrane integrity between the $80 \times 10^{6}$ and $240 \times 10^{6}$ sperm per $\mathrm{ml}$ dilutions in the different extenders $(P>0.05)$. The extenders prepared with LDLs presented higher spermatozoa plasma membrane integrity values than those prepared with egg yolk $(P<0.05)$.

\section{Acrosome integrity}

Acrosome integrity: dilution at $240 \times 10^{6}$ sperm per $m l$. Table 3 displays the mean percentages of acrosome integrity of spermatozoa diluted at $240 \times 10^{6}$ sperm per $\mathrm{ml}$ in the four extenders (TEG, TE, $\mathrm{LDL}^{+}$and $\mathrm{LDL}^{-}$) over 8 days at $4{ }^{\circ} \mathrm{C}$. The initial value recorded in fresh semen (day 0 ) was $87.5 \pm 2.6 \%$. A gradual decrease in acrosome integrity was recorded from day 1 until day 8 . On day 2 , the acrosome integrity percentages were significantly lower than the initial value recorded in fresh semen $(P<0.004)$. The acrosome integrity percentages (Table 3 ) obtained with the $\mathrm{LDL}^{+}$and $\mathrm{LDL}^{-}$extenders were higher than the values obtained with TEG and TE, although the differences were not statistically significant until day $5(P>0.05)$. Between days 6 and 8 , the acrosome integrity percentages obtained with TE, $\mathrm{LDL}^{+}$and $\mathrm{LDL}^{-}$ were higher than the values obtained with TEG $(P<0.05)$.

Acrosome integrity: dilution at $80 \times 10^{6}$ sperm per $m l$. Table 3 shows the mean percentages of spermatozoa acrosome integrity at a dilution of $80 \times 10^{6}$ sperm per $\mathrm{ml}$ in each of the four extenders (TEG, TE, $\mathrm{LDL}^{+}$

Table 3 Mean ( \pm s.d.) percentage of acrosome integrity at $240 \times 10^{6}$ and $80 \times 10^{6}$ sperm per $\mathrm{ml}$ in extenders TEG, TE, $\mathrm{LDL}^{+}$and $\mathrm{LDL}^{-}, \mathrm{over}^{\mathrm{T}}$ the 8 days at $4{ }^{\circ} \mathrm{C}$

\begin{tabular}{|c|c|c|c|c|c|c|c|c|}
\hline \multirow{2}{*}{ Days } & \multicolumn{4}{|c|}{$240 \times 10^{6}$ sperm per $\mathrm{ml}$ in extenders } & \multicolumn{4}{|c|}{$80 \times 10^{6}$ sperm per $\mathrm{ml}$ in extenders } \\
\hline & $T E G$ & $T E$ & $L D L^{+}$ & $L D L^{-}$ & $T E G$ & $T E$ & $L D L^{+}$ & $L D L^{-}$ \\
\hline 0 & $87.5 \pm 2.6^{\text {xa }}$ & $87.5 \pm 2.6^{\text {хa }}$ & $87.5 \pm 2.6^{\text {xa }}$ & $87.5 \pm 2.6^{\text {xa }}$ & $87.5 \pm 2.6^{\mathrm{xc}}$ & $87.5 \pm 2.6^{\mathrm{xc}}$ & $87.5 \pm 2.6^{\mathrm{xc}}$ & $87.5 \pm 2.6^{x c}$ \\
\hline 1 & $82.7 \pm 5.8^{x a}$ & $84.3 \pm 3.0^{x a}$ & $84.1 \pm 5.6^{\text {xa }}$ & $84.5 \pm 2.0^{\times a}$ & $81.8 \pm 6.3^{x c}$ & $82.6 \pm 4.7^{x c}$ & $85.4 \pm 5.9^{x c}$ & $86.2 \pm 3.1^{x c}$ \\
\hline 2 & $79.6 \pm 5.3^{\text {yа }}$ & $81.5 \pm 2.6^{\text {ya }}$ & $82.3 \pm 4.8^{\text {ya }}$ & $82.0 \pm 3.1^{\text {ya }}$ & $78.3 \pm 6.3^{\mathrm{yc}}$ & $80.0 \pm 5.1^{\mathrm{yc}}$ & $82.6 \pm 5.0^{\mathrm{yc}}$ & $83.4 \pm 3.1^{\mathrm{yc}}$ \\
\hline 3 & $76.7 \pm 7.2^{y b}$ & $78.8 \pm 4.2^{\text {уа }}$ & $80.6 \pm 5.3^{\text {yа }}$ & $81.2 \pm 4.1^{\text {yа }}$ & $75.1 \pm 7.7^{\text {ус }}$ & $78.1 \pm 5.7^{\text {ус }}$ & $82.2 \pm 5.5^{\mathrm{yc}}$ & $82.8 \pm 3.2^{y c}$ \\
\hline 4 & $73.8 \pm 9.0^{\mathrm{yb}}$ & $75.8 \pm 6.0^{\text {yа }}$ & $77.4 \pm 5.9^{\text {ya }}$ & $78.0 \pm 6.4^{\text {ya }}$ & $73.3 \pm 7.8^{y c}$ & $75.9 \pm 6.6^{y c}$ & $80.0 \pm 5.8^{y c}$ & $80.7 \pm 4.3^{\mathrm{yc}}$ \\
\hline 5 & $68.8 \pm 8.4^{\mathrm{yb}}$ & $70.5 \pm 4.9^{y a}$ & $70.8 \pm 6.6^{\text {ya }}$ & $72.1 \pm 5.7^{\text {ya }}$ & $69.3 \pm 8.4^{y c}$ & $70.7 \pm 5.7^{\mathrm{yc}}$ & $77.9 \pm 5.1^{\mathrm{yc}}$ & $76.4 \pm 3.2^{y c}$ \\
\hline 6 & $54.0 \pm 20.6^{\mathrm{yb}}$ & $63.3 \pm 7.0^{y b}$ & $63.7 \pm 8.6^{\mathrm{yb}}$ & $69.7 \pm 9.3^{\text {ya }}$ & $61.5 \pm 19.1^{\mathrm{yc}}$ & $67.0 \pm 7.3^{\mathrm{yc}}$ & $73.3 \pm 6.9^{y c}$ & $71.2 \pm 6.0^{\mathrm{yc}}$ \\
\hline 7 & $45.8 \pm 23.9^{y b}$ & $56.1 \pm 6.9^{y b}$ & $56.7 \pm 14.3^{\mathrm{yb}}$ & $61.8 \pm 9.1^{\text {ya }}$ & $54.6 \pm 18.7^{y d}$ & $59.2 \pm 8.8^{y d}$ & $69.7 \pm 8.5^{\mathrm{yc}}$ & $66.2 \pm 5.2^{\mathrm{yc}}$ \\
\hline 8 & $27.0 \pm 16.4^{\mathrm{yb}}$ & $41.6 \pm 9.7^{y b}$ & $42.5 \pm 19.5^{y b}$ & $46.4 \pm 8.0^{\text {ya }}$ & $43.7 \pm 19.7^{\mathrm{yc}}$ & $50.2 \pm 8.0^{y d}$ & $62.8 \pm 9.9^{y c}$ & $60.1 \pm 4.4^{\mathrm{yc}}$ \\
\hline
\end{tabular}

Abbreviations: $\mathrm{LDL}^{+}, \mathrm{LDL}$ with glyceroland; $\mathrm{LDL}^{-}, \mathrm{LDL}$ without glycerol; TE, Tris-egg yolk without glycerol; TEG, Tris-egg yolk-glycerol.

a, b Differences $(P<0.05)$ between the extenders TEG, TE, $\mathrm{LDL}^{+}$and $\mathrm{LDL}^{-}$at $240 \times 10^{6}$ sperm per $\mathrm{ml}$.

c, d Differences $(P<0.05)$ between the extenders TEG,TE, $\mathrm{LDL}^{+}$and $\mathrm{LDL}^{-}$at $80 \times 10^{6}$ sperm per ml within a same time period.

$x, y$ Differences $(P<0.05)$ between the initial value of acrosome integrity and the values in the refrigeration period ( 8 days). 
and $\mathrm{LDL}^{-}$) over 8 days at $4{ }^{\circ} \mathrm{C}$. The initial value recorded in fresh semen (day 0 ) was $87.5 \pm 2.6 \%$. In a similar manner to that described for the previous concentration, a gradual decrease in acrosome integrity was observed from day 1 to day 8 . On day 2 , the acrosome integrity percentages were significantly lower than the initial value recorded in fresh semen $(P<0.004)$. The values obtained with $\mathrm{LDL}^{+}$and $\mathrm{LDL}^{-}$ (Table 3 ) were consistently higher than those obtained with TEG and TE, although the differences were only significant from day 5 to day 8 .

ANOVA confirms the significant effect of time on acrosome integrity. No significant differences were detected between the two semen concentrations used. The presence or absence of glycerol in the extenders did not have any significant effect on acrosome integrity. $\mathrm{LDL}^{+}$ and $\mathrm{LDL}^{-}$gave consistently higher acrosome integrity values than TEG and TE throughout the refrigeration period.

\section{DISCUSSION}

This study investigated the effects of the LDL extender (prepared in our laboratory, purity of 97\%) on sperm motility, spermatozoa plasma membrane integrity and acrosome integrity in semen stored at $4{ }^{\circ} \mathrm{C}$ for 8 days and diluted at two different concentrations, $80 \times 10^{6}$ and $240 \times 10^{6}$ sperm per $\mathrm{ml}$.

The refrigeration process includes a temperature reduction from 37 to $4{ }^{\circ} \mathrm{C}$, which reduces cellular metabolic activity and increases the life span of spermatozoa. ${ }^{3}$ However, the temperature reduction induces membrane stress; probably because of phase changes within the lipid bilayer that affects the functional state of membranes. ${ }^{16}$ The results of this study show that sperm motility, plasma membrane integrity and acrosome integrity decreased with increasing length of storage. The spermatozoa retain similar motility and membrane integrity to fresh semen (day 0) until the second day of refrigeration; on the third day, these values decreased to a statistically significant extent for all of the extenders, namely, TEG, TE, $\mathrm{LDL}^{+}$and $\mathrm{LDL}^{-}$.

These results are coincident with the gradual decline in sperm motility and plasma membrane integrity reported by Nair et al. ${ }^{23}$ in bull and buffalo spermatozoa during refrigeration, and Kasimanickam et al..$^{24}$ observed similar results in ram spermatozoa during storage at $4{ }^{\circ} \mathrm{C}$ in semen diluted in an egg yolk-based extender.

The third parameter, acrosome integrity, also gradually declined over time. However, spermatozoa diluted in the four extenders only conserved similar acrosome integrity values to those recorded in fresh semen until the first day of refrigeration; on the second day, the reduction in these values was statistically significant with respect to the initial results, which could suggest that the acrosome membrane is slightly more susceptible to cold shock than the rest of sperm components. ${ }^{25}$ It is well known that when cooled to between 0 and $15^{\circ} \mathrm{C}$, bull spermatozoa show reduced motility and metabolic activity, ${ }^{26}$ which explains the gradual decrease, observed during the storage period, of the three parameters analyzed here. The analysis of our results confirms the significant effect exerted by time on sperm motility, plasma membrane integrity and acrosome integrity during the refrigeration period ( 8 days). This effect has been observed in semen from different species, but only after $48-96 \mathrm{~h}$ of refrigeration. ${ }^{24,27-29}$ However, little information is available about the effect of refrigeration on bull spermatozoa; the significant progress seen in cryopreservation techniques and the success of AI with frozen-thawed bull semen will probably lead to abandon of refrigeration techniques. However, it is not always possible to maintain sperm motility and functionality of elite bull by cryopreservation and it is not easy to find liquid nitrogen in some countries. Consequently refrigeration techniques cannot be totally given up. Aurich ${ }^{30}$ also remarks the advantage of refrigeration as an economic technique that provides maintenance of semen for insemination purposes.

The comparison of the results obtained with bull semen refrigerated in different extenders indicates that those containing LDLs had a significantly superior effect on spermatozoa motility, plasma membrane integrity and acrosome integrity in comparison with extenders prepared with egg yolk. The protective action of LDLs has been shown in ram spermatozoa stored at $4{ }^{\circ} \mathrm{C},{ }^{31,32}$ the author concluded that the LDL binds to the cell membrane protecting it from 'cold shock'. Another advantage of the LDL extender over a standard egg yolk extender is that it has a less complex chemical composition, which is clearly defined and stable. ${ }^{10}$ The results also show that the presence or absence of glycerol in the refrigeration extenders has no effect on acrosome integrity; this finding is coincident with that of Hirai et al., ${ }^{33}$ whose study showed that the percentage of motile spermatozoa in bull semen was unaffected by the presence of glycerol in the extender, the authors postulate that glycerol probably has a more important role during freezing-thawing than during refrigeration. Used in an inadequate concentration, glycerol has a toxic effect on the spermatozoa cells and causes damages to the spermatozoa, reducing motility after the freeze thaw process. ${ }^{1}$ Glycerol is usually used at the concentration of $6 \%$ in extenders. However, the tolerance of spermatozoa to glycerol differs according to species. This interspecific difference would be probably due to the difference between species on plasma membrane permeability. Our study shows for the first time that the toxicity of glycerol, expressed by a reduction of motility, after 8 days of time exposure, is more important in the presence of egg yolk, whereas no effect of glycerol toxicity was observed in the LDL extender. This result is probably because of the mechanism of protection of LDLs on spermatozoa. Hammerstedt and Graham ${ }^{34}$ suggest that glycerol would fit in the lipid bilayer of the plasma membrane of spermatozoa, modifying the membrane fluidity and the intracellular viscosity. LDLs should reduce the deleterious effect of glycerol on the cells by a mechanism that is still unknown.

The concentration of the semen used had a significant effect on spermatozoa motility and the deterioration of membrane functionality. The two concentrations compared over the 8-day period were $80 \times 10^{6}$ and $240 \times 10^{6}$ sperm per $\mathrm{ml}$, and the previously described parameters were recorded. The results show that the changes in spermatozoa motility and membranes functionality were less marked at $80 \times 10^{6}$ sperm per $\mathrm{ml}$ than at $240 \times 10^{6}$ sperm per $\mathrm{ml}$, the reduction observed in these parameters was more significant at the end of the refrigeration period (day 8), especially at $240 \times 10^{6}$ sperm per ml. This could suggest that at the beginning of the incubation period at $4{ }^{\circ} \mathrm{C}$ (day 2 or 3), the higher seminal plasma volume, at $240 \times 10^{6}$ sperm per $\mathrm{ml}$, has a protective effect on the sperm, which subsequently declines over time. The possible physiological reasons for this decline might be extracellular oxidative stress resulting in the production of free radicals, which has been associated with lipid peroxidation. Nair et al. ${ }^{23}$ quantified the antioxidant enzyme activity in the spermatozoa and seminal plasma of cattle and buffalos; the results showed that the lower levels of activity of antioxidant enzymes in buffalo spermatozoa were due to the higher lipid peroxidation of sperm membranes. Indeed, the oxidative stress induces aging of spermatozoa and reduces its functionality. ${ }^{35}$ The activities of antioxidant enzymes have been shown to decline successively in spermatozoa and increase in the seminal plasma, ${ }^{23}$ which could explain the differences observed at $80 \times 10^{6}$ and $240 \times 10^{6}$ sperm per $\mathrm{ml}$ on the parameters evaluated in this study.

The higher volume of seminal plasma would seem to be beneficial for cryopreservation, ${ }^{11}$ but not for refrigeration at $4{ }^{\circ} \mathrm{C}$ for more than 3 
days; this could be due to the accumulation of reactive oxygen species. Spermatozoa quality is therefore better preserved at the lower concentration.

It is well known that semen storage requires the accurate control of various parameters, notably semen dilution; given the interactions between the sperm and the nutritive components of the medium, it is important that the semen be diluted immediately after collection. Another important factor is the storage temperature when sperm functionality needs to be maintained for a given period, for example, to allow transport or delay the AI procedure; the refrigeration at $4{ }^{\circ} \mathrm{C}$ for bull seems to be adequate, as it reduces spermatozoal metabolism thus economizing energy resources and preserving spermatozoal functionality, the latter being restored after warming to $37{ }^{\circ} \mathrm{C} .{ }^{36} \mathrm{~A}$ third essential parameter for maintaining spermatozoal vitality is the presence of lipoproteins in the extenders which act as membrane protectors. ${ }^{37}$

In conclusion, our results show that $8 \%$ LDLs provides superior preservation of spermatozoal motility and membrane functionality at $4{ }^{\circ} \mathrm{C}$ over 8 days at a dilution of $80 \times 10^{6}$ sperm per $\mathrm{ml}$ than the other extenders tested.

This finding could be used to define a policy for the storage of bull semen with high quality. However, further in vivo studies are needed to determine the post-refrigeration fertility of the semen.

\section{AUTHOR CONTRIBUTIONS}

O. V.-M., D. T. and L. B.-A. design the experiment. O. V.-M.write the paper, collect and analyse the data, and perform the experiments. L. B.-A. correct the paper and supervise the study. D. B. read and correct the paper. C. T. analyse the data. E. S. and S. D. provides the CASA analyser. M. A. contributes to the LDL extraction of the extender used and scientific suggestions. D. T. is the director of the reserach unit.

\section{COMPETING FINANCIAL INTERESTS}

The authors declare no competing financial interests.

\section{ACKNOWLEDGMENTS}

We thank the Veterinary Faculty of the Central University of Venezuela for their support and advice. We also thank the Fundayacucho Foundation.

1 Medeiros CM, Forell F, Oliveira AT, Rodrigues JL. Current status of sperm cryopreservation: why isn't it better. Theriogenology 2002; 57: 327-44.

2 Salamon S, Maxwell WM. Storage of ram semen. Anim Reprod Sci2000; 62: 77-111.

3 Barbas JP, Mascarenhas RD. Cryopreservation of domestic animal sperm cells. Cell Tissue Bank 2009; 10: 49-62.

4 Chantler E, Abraham-Peskir JV, Little S, McCann C, Medenwaldt R. Effect of cooling on the motility and function of human spermatozoa. Cryobiology 2000; 41: 125-34.

5 Parks JE. Hypothermia and mammalian gametes. In: Karow AM, Critser JK, editors. Reproductive Tissue Banking. San Diego: Academic Press; 1997. pp229-61.

6 Foote RH. Buffers and extenders: what do they do? why are they important? Proceedings of Technical Conference on Artificial Insemination and Reproduction. Columbia, MO: National Association of Animal Breeders; 1984. pp62-70.

7 Pace MM, Graham EF. Components in egg yolk which protect bovine spermatozoa during freezing. J Anim Sci 1974; 39: 1144-9.

8 Demianowicz W, Strezek J. The effect of lipoprotein fraction of egg yolk on some of the biological properties of boar spermatozoa during storage of the semen in liquid state. Reprod Domest Anim 1996; 31: 279-80.

9 Moussa M, Martinet V, Trimeche A, Tainturier D, Anton M. Low density lipoproteins extracted from hen egg yolk by an easy method: cryoprotective effect on frozen-thawed bull semen. Theriogenology 2002; 57: 1695-706.
10 Amirat L, Tainturier D, Jeanneau L, Thorin C, Gerard O et al. Bull semen in vitro fertility after cryopreservation using egg yolk LDL: a comparison with Optidyl, a commercial egg yolk extender. Theriogenology 2004; 61: 895-907.

11 Vera-Munoz O, Amirat-Briand L, Diaz T, Vasquez L, Schmidt E et al. Effect of semen dilution to low-sperm number per dose on motility and functionality of cryopreserved bovine spermatozoa using low-density lipoproteins (LDL) extender: comparison to Triladyl and Bioxcel. Theriogenology 2009; 71: 895-900.

12 Aisen E, Medina V, Venturino A. Cryopreservation and post thawed fertility of ram semen frozen in different trehalose concentrations. Theriogenology 2002; 57: 1801-8.

13 Amann RP. Cryopreservation of sperm. In: Knobil E, Neill JD, editors. Encyclopedia of Reproduction. Burlington, MA: Academic Press; 1999. pp773-83.

14 Kundu CN, Chakraborty J, Dutta P, Bhattacharyya D, Ghosh A et al. Effects of dextrans on cryopreservation of goat cauda epididymal spermatozoa using a chemically defined medium. Reproduction 2002; 123: 907-13.

15 Salisbury GW, VanDemark NL, Lodge JR. Physiology of Reproduction and Artificial Insemination in the Bull. Chapter 17: Techniques of Semen Freezing. 2nd ed. Saragossa: ACRIBIA; 1978. pp518-80.

16 Watson PF. The causes of reduced fertility with cryopreserved semen. Anim Reprod Sci 2000; 60-61: 481-92.

17 Benson RW, Sexton TJ, Pickett BW, Lucas JJ, Gebauer MR. Influence of processing techniques and dilution rates on survival of frozen bovine spermatozoa. University of Connecticut: Storrs Mansfield, CT, USA, 1968. Agr Exp Sta Res. Rep. no. 28.

18 Chenoweth PJ, Hopking FM, Spiter JC, Larsen RE. Guidelines for using the bull breeding soundness evaluation form. In: Theriogenology Handbook, Vol. B-10. Hasting, , NE: SFT; 1993. pp1-5.

19 Jeyendran RS, van der ven HH, Pérez Peláez M, Crabo BG, Zaneveld LJ. Development of an assay to assess the functional integrity of the human sperm membrane and its relationship to the other semen characteristics. J Reprod Fertil 1984; 70: 219-28.

20 Ballester J, Johannisson A, Saravia F, Haard M, Gustafsson H. Post-thaw viability of bull Al-doses with low-sperm numbers. Theriogenolgy 2007; 68: 934-43.

21 Foote Rh, Kaproth MT. Sperm numbers inseminated in dairy cattle and nonreturn rates revisited. J Dairy Sci 1997; 80: 3072-6.

22 Mendoza C, Carreras A, Moos J, Tesark J. Distinction between true acrosome reaction and degenerative acrosome loss by a one step staining method using Pissum sativum agglutinin. J Reprod Fertil 1992; 95: 755-63.

23 Nair SJ, Brar AS, Ahuja CS, Sangha SP, Chaudhary KC. A comparative study on lipid peroxidation, activities of antioxidant enzymes and viability of cattle and buffalo bull spermatozoa during storage at refrigeration temperature. Anim Reprod Sci 2006; 96 : 21-9.

24 Kasimanickam R, Kasimanickam V, Pelzer KD, Dascanio JJ. Effect of breed and sperm concentration on the changes in structural, functional and motility parameters of ramlamb spermatozoa during storage at 4 degrees C. Anim Reprod Sci 2007; 101: 60-73.

25 Purdy PH. A review on goat sperm cryopreservation. Small Rumin Res 2006; 6: 215-25.

26 Darin-Bennett A, White IG. Influence of the cholesterol content of mammalian spermatozoa on susceptibility to cold-shock. Cryobiology 1977; 14: 466-70.

27 Althouse GC, Wilson ME, Kuster C, Parsley M. Characterization of lower temperature storage limitations of fresh-extended porcine semen. Theriogenology 1998; 50: 535-43.

28 Graham LH, Bando J, Gray C, Buhr MM. Liquid storage of Asian elephant (Elephas maximus) sperm at 4 degrees C. Anim Reprod Sci 2004; 80: 329-40.

29 Shahiduzzaman AK, Linde-Forsberg C. Induced immotility during long term storage at $5^{\circ} \mathrm{C}$ does not prolong survival of dog spermatozoa. Theriogenology 2007; 68: 920-33.

30 Aurich C. Recent advances in cooled-semen technology. Anim Reprod Sci2008; 107: 268-75.

31 Watson PF. The roles of lipid and protein in the protection of ram spermatozoa at 5 degrees C by egg-yolk lipoprotein. J Reprod Fertil 1981; 62: 483-92.

32 Bencharif D, Tainturier D, Vialtelle C, Amirat-Briand L, Schmitt E et al. The association of glutamine with low density lipoprotein (LDL) in cooling canine sperm: preliminary results. Proceedings of the 6th International Symposium on Canine and Feline Reproduction; 9-11 July 2008, Vienna, Austria. University of Veterinary Medicine Vienna: Vienna, Austria; 2008.

33 Hirai M, Cerbito WA, Wijayagunawardane MP, Braun J, Leidi W et al. The effect of viscosity of semen diluents on motility of bull spermatozoa. Theriogenology 1997; 47: 1463-78.

34 Hammerstedt RH, Graham JK. Cryopreservation of poultry sperm the enigma of glycérol. Cryobiology 1992; 29: 26-38.

35 Upreti GC, Jensen K, Munday R, Vishwanath R, Smith JF. Studies on ram spermatozoal aromatic amino acid oxidase. Proc Aust Soc Reprod Biol 1994; 26 : 115.

36 Dumont $\mathrm{P}$, Maitre $\mathrm{P}$, Guerin $\mathrm{B}$. Effect of glycerol concentration and egg yolk on bull semen preservation at $4^{\circ} \mathrm{C}$. Breed Insemin 1995; 268: 13-28.

37 Decuadro-Hansen G. Refrigeration and freezing semen: experiments in animals. Gyne col Obste t Fert 2004; 32: 887-93. 